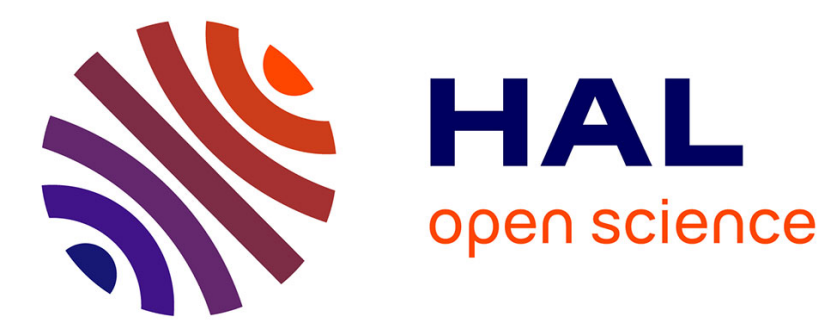

\title{
Pharmacological dissection of the paradoxical pain induced by a thermal grill.
}

Delphine Kern, Emilie Pelle-Lancien, Virginie Luce, Didier Bouhassira

\section{To cite this version:}

Delphine Kern, Emilie Pelle-Lancien, Virginie Luce, Didier Bouhassira. Pharmacological dissection of the paradoxical pain induced by a thermal grill.. Pain, 2008, 135 (3), pp.291-9. 10.1016/j.pain.2007.12.001 . inserm-00313770

HAL Id: inserm-00313770 https://www.hal.inserm.fr/inserm-00313770

Submitted on 27 Aug 2008

HAL is a multi-disciplinary open access archive for the deposit and dissemination of scientific research documents, whether they are published or not. The documents may come from teaching and research institutions in France or abroad, or from public or private research centers.
L'archive ouverte pluridisciplinaire $\mathbf{H A L}$, est destinée au dépôt et à la diffusion de documents scientifiques de niveau recherche, publiés ou non, émanant des établissements d'enseignement et de recherche français ou étrangers, des laboratoires publics ou privés. 


\section{PHARMACOLOGICAL DISSECTION OF THE PARADOXICAL PAIN INDUCED BY A THERMAL GRILL}

Delphine KERN ${ }^{1}$, Emilie PELLE-LANCIEN ${ }^{1}$, Virginie LUCE $^{1}$ and Didier BOUHASSIRA ${ }^{1,2}$

1) INSERM U-792, Boulogne-Billancourt F-92100 France; CHU Ambroise Pare, APHP, Boulogne-Billancourt, F-92100 France; 2) Université Versailles-Saint-Quentin, Versailles F-78035, France.

Corresponding author: Didier Bouhassira MD, PhD.

INSERM U-792

Centre d'Evaluation et de Traitement de la Douleur CHU Ambroise Paré

9, avenue Charles de Gaulle 92100 BOULOGNE-BILLANCOURT, FRANCE

Tel: $\quad+33149094556$

Fax: + 33149094435

e-mail: didier.bouhassira@apr.aphp.fr 


\section{ABSTRACT}

We investigated the role of the glutamatergic and endogenous opioidergic systems in the paradoxical pain evoked by the simultaneous application of innocuous warm and cold stimuli to the skin with a "thermal grill".

Two parallel randomized, double blind, cross-over studies, including two groups of 12 healthy volunteers, were carried out to compare the effects of iv ketamine or naloxone to those of placebo, on the sensations produced by a thermode (i.e. thermal grill) composed of six bars applied on the palmar surface of the right hand. The temperature of alternate (even and odd numbered) bars could be controlled independently by Peltier elements to produce various patterns of the grill. During each experimental session we measured the effects of ketamine, naloxone or placebo on the intensity of: i) paradoxical pain; ii) "normal" thermal (heat and cold) pain; and iii) non painful thermal (warm and cool) sensations.

Ketamine administration resulted in a significant reduction of paradoxical pain intensity but did not alter normal pain or non painful thermal sensations. By contrast, naloxone had no effect on paradoxical pain, normal pain or non painful thermal sensations.

This study demonstrates for the first time that the "thermal grill illusion of pain" can be modulated pharmacologically. This paradoxical pain, which involves the glutamatergic systems, acting through the NMDA receptors, but not the tonic endogenous opioids systems, might share some mechanisms with pathological pain. 


\section{1- INTRODUCTION}

The experimental analysis of perceptive illusions and paradoxical sensations has contributed significantly to our understanding of both sensory physiology and pathophysiology (Gregory, 1997). However, there have been very few such studies addressing pain. The paradoxical burning sensation evoked by the simultaneous application of innocuous cutaneous warm and cold stimuli with a "thermal grill" is a unique experimental phenomenon comparable to an illusion of pain. Despite its potential value for studying pain mechanisms and the interactions between the nociceptive and thermal sensory systems, this phenomenon has attracted only intermittent attention from researchers since its description more than a century ago by Thunberg (1896).

The psychophysical characteristics of this paradoxical sensation and its perceptual quality and place in the sensory spectrum were debated during the first part of the XXth century (Boring, 1942). In particular, several early authors questioned the specificity and the painful quality of this sensation (e.g. Jenkins et al., 1938a, b). This phenomenon was reinvestigated recently using modern techniques, to identify causative conditions and to characterize further its psychophysical properties. Non painful "synthetic heat" has been reported (Green, 2002; Fruhstorfer et al., 2003), but it has been repeatedly demonstrated that, with appropriate stimuli parameters, stimulation with a thermal grill composed of alternate warm and cold bars also induces a painful burning sensation (Craig and Bushnell, 1994; Bouhassira et al., 2005; Leung et al., 2005). In particular, we showed in a large group of volunteers that the occurrence and intensity of this paradoxical pain were directly related to the magnitude of the difference in the temperatures between the warm and cold bars of the grill; this suggests that pain can be the result of the simple 
addition of two non-noxious, normally non-painful, thermal stimuli (Bouhassira et al., 2005).

The mechanisms of this "thermal grill illusion of pain" are still unclear. Electrophysiological studies in animals and complementary psychophysical and neuroimaging studies in humans led to the suggestion that this phenomenon resulted from the reduction of the inhibition normally exerted by the cold afferents on the nociceptive systems (Craig and Bushnell, 1994, Craig et al., 1996).

We report a study with healthy volunteers to investigate the neuropharmacological basis of the paradoxical burning pain sensation evoked by the thermal grill. We tested the possible involvement of the glutamatergic and endogenous opioid systems, because these neurotransmitter systems are widely expressed throughout the somatosensory systems and are involved in the transmission and modulation of pain signals (Salt and Eaton, 1996; Bodnar and Klein, 2003; Fundytus, 2001). We analyzed the effects of two treatments on paradoxical burning pain, normal (physiological) thermal pain and non painful thermal sensations induced by a thermal grill: the treatments were the $\mathrm{N}$-methyl-D-aspartate (NMDA) receptor antagonist, ketamine, and the opioid receptor antagonist, naloxone, administered intravenously according to a randomized, double-blind, placebocontrolled, cross-over design. 


\section{2- METHODS}

Following approval by the Ambroise Paré hospital Ethics Committee, two parallel pharmacological studies were performed in two groups of 12 paid healthy volunteers naive for thermal grill effects. The participants, were carefully briefed about the experimental procedures and gave informed written consent.

\subsection{Equipment}

As in our previous study (Bouhassira et al. 2005), thermal stimuli were produced with a thermode designed and built by SEICER (Mouy, France). The thermode was composed of six bars $(1.2$ by $16 \mathrm{~cm})$ covered with a copper plate, spaced $2 \mathrm{~mm}$ apart for thermal isolation, whose temperature was controlled by thermoelectric Peltier elements (three per bar). The temperatures of alternate (evenand odd-numbered) bars were monitored independently in the $5-50{ }^{\circ} \mathrm{C}$ range to produce various combinations of temperatures (i.e. patterns of the 'thermal grill'). Thermistors placed in each bar provided continuous temperature feedback of the thermode-skin interface (resolution $\pm 0.3^{\circ} \mathrm{C}$ ).

\subsection{Study design}

The same procedure was used in the two studies, which were organised as randomised, double-blind, placebo controlled, cross-over trials.

In study 1 , the volunteers were randomly assigned to receive either an intravenous (iv) injection of ketamine or placebo (saline). Ketamine was administered as a bolus of $0.2 \mathrm{mg} / \mathrm{kg}$ over 10 min followed by a continuous infusion of $6 \mu \mathrm{g} / \mathrm{kg} / \mathrm{min}$ until the end of the measurements (i.e. 30-35 minutes).

In study 2, the volunteers were randomly assigned to receive an iv injection of naloxone or placebo (saline). Naloxone was administered as a bolus of $0.1 \mathrm{mg} / \mathrm{kg}$ 
over 1 minute followed by a continuous infusion of $0.1 \mathrm{mg} / \mathrm{kg} / \mathrm{h}$ until the end of the measurements (i.e. 30-35 minutes).

In both studies, the volume and rate of infusion of the placebo was similar to that of the active drug. The infusions were prepared by a nurse who was not further involved in the experiment. The doses of ketamine and naloxone were chosen on the basis of the numerous previous studies using these drugs in various experimental and clinical pain models (e.g. Buchsbaum et al., 1977; Levine et al., 1979; Grevert et al., 1983; Guirimand et al., 2000; Brennum et al., 2001; Anderson et al., 2002, Bossard et al., 2002; Strigo et al., 2005).

\subsection{Experimental procedures}

Each volunteer participated in two experimental sessions separated by an interval of one week. All experiments were performed at a constant temperature $\left(21^{\circ} \mathrm{C}\right)$ and the thermal stimuli were applied to the palmar surface of the right hand. As described previously (Bouhassira et al., 2005) the temperature of the warm and cold bars was set prior to each stimulus. Then, the volunteers were asked to apply their hand to the grill, orthogonally to the long axis of the bars and each stimulus was applied for 30 seconds.

During each experimental session the following measures were performed before (control period) and from 5 minutes after the end of the administration of the bolus of ketamine, naloxone or placebo:

i) Determination of the cold pain threshold (CPT) and the heat pain threshold (HPT), with a staircase algorithm. In this procedure, even-numbered bars were kept at the neutral temperature while the temperature of the odd-numbered bars was changed randomly (increased or decreased) by steps of 3 to $0.5^{\circ} \mathrm{C}$. After each stimulus the subjects had to report whether they perceived the stimulus as painful or 
not. If the response was negative, the next temperature step was $3^{\circ} \mathrm{C}$; if the response was positive subsequent temperature steps (increase or decrease) was $0.5^{\circ} \mathrm{C}$ until the first non-painful sensation was reported.

ii) Determination of the combination of thermal stimuli producing paradoxical pain, defined as a painful sensation produced by a combination of warm and cool stimuli, the intensity of each of which was in the non painful range. A series of stimuli combining cold $\left(\mathrm{CPT}+2^{\circ} \mathrm{C},+4^{\circ} \mathrm{C}\right.$ or $\left.+6^{\circ} \mathrm{C}\right)$ and warm $\left(\mathrm{HPT}-2^{\circ} \mathrm{C},-4^{\circ} \mathrm{C}\right.$ or $\left.-6^{\circ} \mathrm{C}\right)$ non noxious stimuli were applied to define the optimal pattern of the thermal grill producing a paradoxical pain in each subject. These parameters were based on our previous results showing that the intensity of paradoxical pain was directly related to the difference in the intensity of the warm and cool bars of the grill (Bouhassira et al., 2005). Then, two measures of paradoxical pain separated by a 3 minute-interval were taken as baseline control values with these parameters. After each stimulus, the volunteers were asked to describe the quality of their sensations (burning pain, painful cold, priking, cramp-like, other) and to rate the intensity of paradoxical pain and its unpleasantness on two different $100 \mathrm{~mm}$ visual analog scales (VAS), one graduated from "no pain"-to "worst possible pain" and the other from "not unpleasant" to "very unpleasant". Volunteers who who did not report any paradoxical painful sensation or had an unstable response during the control period on the first experimental day (i.e. a variation in paradoxical pain intensity $\geq 30 \%$ between the two consecutive stimuli), were not included in the study.

iii) Measurement of the intensity of the non painful warm and cold sensations evoked by two successive stimuli corresponding to the components of the grill used to produce the paradoxical painful sensation. The even-numbered bars were kept at the neutral temperature while the temperature of the odd-numbered bars was set at 
the temperature of the warm or the cold component of the combination used in the previous step to produce the paradoxical pain. After each stimulus, the volunteers were asked to rate the intensity of the warm or cold sensations on a $100 \mathrm{~mm}$ VAS graduated from "not warm" to "very warm" or "not cold" to "very cold".

iv) Measurement of the intensity of normal pain evoked by one suprathreshold heat stimulus and one suprathreshold cold stimulus. In this test, the even-numbered bars were kept at the neutral temperature while the temperature of the oddnumbered bars was set at $2^{\circ} \mathrm{C}$ above the HPT or $2^{\circ} \mathrm{C}$ below the CPT. After each stimulus, the volunteers were asked to rate the intensity of pain on a $100 \mathrm{~mm}$ VAS graduated from "no pain" to "worst possible pain".

Blood pressure, heart rate and $\mathrm{SaO}_{2}$ were monitored during each session. Side effects such as nausea, vomiting, sedation, dysphoria and hallucinations were recorded when present. The volunteers were supervised for approximately 2 hours after the infusion was stopped.

\subsection{Statistical analysis:}

Results are expressed as means \pm 1 SD. Changes between baseline and after treatment in paradoxical pain intensity, normal (heat and cold) pain intensity, and non painful (warm and cold) sensations intensity, were compared between the active treatment (ketamine or naloxone) and placebo groups. An analysis of variance (ANOVA), with Fisher's post hoc least significant difference tests, was used with the dependent variable being one the outcome measures and the factors being treatment (active, placebo), period (before or after treatment) and sequence (first or second experimental session). We used Wilcoxon's signed ranks test to compare paired data obtained before and after treatments (i.e. pain thresholds, warm and cold temperatures of the thermal grill). Results were considered significant at $\mathrm{P}<0.05$. 


\section{3- RESULTS}

3.1 Effects of ketamine on the painful and non painful sensations evoked by the thermal grill.

Seventeen volunteers were screened and 12 volunteers $(6$ men and 6 women aged 21-38 years) completed the two sessions of the study. Five volunteers were not included because either no paradoxical pain could be evoked or its intensity was not stable during the control period of the first experimental session. The mean dose of ketamine administered intravenously was $29.8 \pm 5.4 \mathrm{mg}$ (range: 24.0 - $44.8 \mathrm{mg}$ ).

The heat and cold pain thresholds were similar before the administration of ketamine $\left(\mathrm{HPT}=42.6 \pm 2.2^{\circ} \mathrm{C}\right.$ and $\left.\mathrm{CPT}=18.2 \pm 1.9^{\circ} \mathrm{C}\right)$ or placebo $(\mathrm{HPT}=42.8 \pm$ $1.7^{\circ} \mathrm{C}$ and $\mathrm{CPT}=17.8 \pm 1.8^{\circ} \mathrm{C}$ ) and were not significantly different after the treatments $\left(\mathrm{HPT}=44.1 \pm 1.7\right.$ and $\mathrm{CPT}=17.5 \pm 2.8^{\circ} \mathrm{C}$ after ketamine; $\mathrm{HPT}=43.6 \pm$ $1.5^{\circ} \mathrm{C}$ and $\mathrm{CPT}=17.7 \pm 2.3^{\circ} \mathrm{C}$ after placebo).

The combinations of warm and cool temperatures (i.e. components of the thermal grill) used to produce the paradoxical pain at baseline, were similar for the ketamine $\left(39.4 \pm 2.0^{\circ} \mathrm{C}\right.$ and $\left.22.4 \pm 1.5^{\circ} \mathrm{C}\right)$ and placebo groups $\left(38.8 \pm 1.8^{\circ} \mathrm{C}\right.$ and $22.2 \pm 1.4^{\circ} \mathrm{C}$ ). Paradoxical pain was mostly (for $75 \%$ of the stimuli) described as burning pain. Its intensity was significantly more reduced after the injection of ketamine than afer the injection of placebo (Figure $1 \mathrm{~A}$ ). In fact, 10 of the volunteers suffered no paradoxical pain completely after ketamine and, all but one of them (who reported only non painful cold sensation), reported a mixture of warm and cold (non painful) sensations. The unpleasantness of paradoxical pain was also significantly reduced by ketamine (Figure 1B).

In contrast, the intensity of normal pain induced by suprathreshold heat or cold stimuli was not significantly changed by either ketamine or placebo treatments (figure 
$2 A, B)$.

The non painful thermal sensations evoked by stimuli at the warm and cool temperatures used to produce the paradoxical pain were similarly unchanged by ketamine or placebo (figure $3 \mathrm{~A}, \mathrm{~B}$ ).

All the volunteers reported one or more side effects after the administration of ketamine. The most frequent side effects of ketamine were dizziness, $(n=11)$ and/or sedation $(n=5)$, more rarely tinnitus $(n=3)$ or nausea $(n=1)$. These side effects were transitory, always mild in intensity and did not require any specific treatment. Only 1 subject reported a side effect (dizziness) afer placebo.

3.2 Effects of naloxone on the painful and non painful sensations evoked by the thermal grill

Eighteen volunteers were screened and 12 volunteers $(6$ men and 6 women aged 21-38 years) completed the two sessions of the study. Six volunteers were not included because either no paradoxical pain could be evoked or its intensity was not stable during the control period of the first session. Twelve volunteers ( 6 men and 6 women aged 22-27 years) completed the two sessions of the study. The mean dose of naloxone administered intravenously was $8.2 \pm 2.1 \mathrm{mg}$.

The heat and cold pain thresholds were similar before the administration of naloxone $\left(\mathrm{HPT}=43.1 \pm 1.7^{\circ} \mathrm{C}\right.$ and $\left.\mathrm{CPT}=15.8 \pm 2.9^{\circ} \mathrm{C}\right)$ or placebo $(\mathrm{HPT}=43.0 \pm$ $2.1^{\circ} \mathrm{C}$ and $\mathrm{CPT}=15.3 \pm 2.0^{\circ} \mathrm{C}$ ) and were not significantly different after the treatments $\left(\mathrm{HPT}=43.2 \pm 2.1\right.$ and $\mathrm{CPT}=16.8 \pm 2.8^{\circ} \mathrm{C}$ after naloxone; $\mathrm{HPT}=43.6 \pm$ $2.0^{\circ} \mathrm{C}$ and $\mathrm{CPT}=16.5 \pm 2.7^{\circ} \mathrm{C}$ after placebo). The combinations of warm and cool temperatures used to produce the paradoxical pain were similar in the naloxone $\left(39.2 \pm 2^{\circ} \mathrm{C}\right.$ and $\left.20.2 \pm 3.1^{\circ} \mathrm{C}\right)$ and placebo $\left(38.8 \pm 2.3^{\circ} \mathrm{C}\right.$ and $\left.19.0 \pm 2.5^{\circ} \mathrm{C}\right)$ groups.

Neither naloxone nor placebo administration had any significant effect on the 
paradoxical pain evoked by the thermal grill (figure $4 \mathrm{~A}$ ), or normal pain induced by suprathreshold hot and cold stimuli (figure 4B, C). The non painful thermal sensations evoked by the stimuli at the warm and cool temperatures used to produce the paradoxical pain were not significantly altered by the naloxone treatment (VAS scores were: $22.4 \pm 18.5$ for warm and $21.8 \pm 9.7$ for cold before the injection and $22.2 \pm 20$ and $20 \pm 20$ after the injection) or placebo (VAS scores were: $20.1 \pm 19$ for warm and $24.3 \pm 8.7$ for cold before the injection and $19.0 \pm 14.4$ and $19.8 \pm 7.2$ after the injection ).

No side effect were reported with either the placebo or naloxone. 


\section{Discussion}

Here, we report the first study investigating the neuropharmacological basis of the paradoxical burning pain induced by the simultaneous application of adjacent warm and cold innocuous cutaneous stimuli with a thermal grill. The intravenous injection of a low (subanaesthetic) dose of ketamine, a non competitive NMDA receptor antagonist, selectively reduced the intensity of the paradoxical pain induced by the grill, without affecting normal thermal painful or non painful sensations. By contrast, neither the paradoxical or normal pain, nor the non painful sensations evoked by the thermal grill were altered after the injection of the opioid receptor antagonist, naloxone. Thus, paradoxical pain can be modulated pharmacologically and has a pharmacological sensitivity that is different from that of normal pain. The involvement of NMDA receptors might indicate that this unique "illusion of pain" shares some mechanisms with pathological pain.

Our findings confirm the general characteristics of the paradoxical pain produced by a thermal grill described in previous studies (Craig and Bushnell, 1994; Bouhassira et al., 2005; Leung et al., 2005). In particular, we confirmed its predominantly burning quality and its mild to moderate intensity. We also confirmed this phenomenon was not detectable or not reproducible in about of third of subjects (Bouhassira et al., 2005). However, our study shows that this phenomenon is sufficiently stable and reproducible in most volunteers to be used in pharmacological studies.

The mechanisms underlying the paradoxical sensations (painful or not painful) induced by a thermal grill have been a matter for debate for more than a century (Boring, 1942; Craig and Bushnell, 1994; Green 2002; Fruhstorfer et al., 2003, Bouhassira et al., 2005). Although peripheral mechanisms have been proposed 
(Alrutz, 1998), most authors consider that this phenomenon, which illustrates the interactions between the nociceptive and thermosensory systems, depends primarily on central mechanisms. The best-documented hypothesis was proposed by Craig and Bushnell (1994) on the basis of their electrophysiological work in animals and complementary psychophysical and neuroimaging data for humans (Craig et al., 1996). They proposed that the paradoxical burning induced by the thermal grill was due to the reduction of the inhibition exerted physiologically by cold afferents on the nociceptive pathways (probably at the thalamo-cortical level). This thermosensory disinhibition hypothesis was based on electrophysiological recordings of spinal dorsal horn neurones in the cat, indicating that stimulation with the cold bars activates two populations of lamina I neurones: the "COLD" cells, responding specifically to nonnoxious cold stimuli, and the multimodal "HPC" cells, activated by noxious heat and mechanical (i.e. pinch) stimuli and by non noxious cold stimuli below $25^{\circ} \mathrm{C}$ (Craig et al., 2001). The addition of adjacent warm stimuli resulted in a reduction of the activity of COLD cells, but not of HPC neurons, so it was suggested that the burning pain induced by the grill resulted from changes in the pattern of the relative activities of the COLD and HPC neurones (Craig and Bushnell, 1994). Our previous psychophysical results were consistent with this general integrative model, although they were not fully compatible with the details of this otherwise attractive hypothesis (see discussion in Bouhassira et al., 2005).

Alternatively, the painful (and not painful) paradoxical sensations induced by the thermal grill may depend on the convergence and addition of the activities of adjacent cold and warm afferents on CNS multireceptive neurones responding to both nociceptive and non-nociceptive stimuli (Green, 2002; Bouhassira et al., 2005). Consistent with this hypothesis, which is not mutually exclusive with the disinhibition 
theory, numerous cells with a very large range of responses to thermal stimuli (ie Wide Dynamic Range (WDR) neurones) have been recorded in both the spinal cord and thalamus in rats, cats and primates (e.g. Poulos and Benjamin, 1967; Burton, 1975; Price et al., 1978; Yamasoto and Pierau, 1980; Kenshalo et al., 1982; Bushnell et al., 1993; McHaffie et al., 1994; Apkarian and Shi, 1994), although they rarely responded to both cool and warm stimuli (Khasabov et al., 2001). Thus, the perceptual discrimination of the quality and intensity of the sensation might depend on the relative activities of the so-called "labelled sensory lines" (i.e. specific unimodal thermal pathways) and this multimodal intensity channel (Green, 2002; Bouhassira et al., 2005).

These hypotheses are consistent with clinical observations suggesting strong interactions between the nociceptive and thermal sensory systems (Hansen et al., 1996 ; Yosipovitch et al., 1995; Defrin et al., 2002; Ducreux et al., 2006). The pharmacological results we report here indicate that such interactions involve the activation of NMDA receptors, presumably through the release of excitatory aminoacids (i.e. glutamate). NMDA receptors are abundant in the central nervous system (CNS), both in the spinal cord and the brain and the role of excitatory aminoacids, as major transmitters of excitatory synapses throughout the brain, is well established (Mayer and Westbrook, 1981; Collingridge and Lester, 1989). In particular, the role of glutamate and NMDA receptors in spinal and supraspinal transmission, integration and modulation of both nociceptive and non nociceptive somatosensory signals is extensively documented (e.g. Dougherty et al. 1992; Salt and Eaton, 1996). The reduction of paradoxical pain induced by ketamine may be a consequence of its action in the spinal dorsal horn and/or in the brain, particularly in the thalamus where there are numerous glutamate receptors, including the NMDA 
subtype (Salt, 2002). The neuropharmacology of COLD and HPC spinal neurons is not well established, so it is difficult to interpret our results directly within the framework of the thermosensory disinhibition theory. Interestingly, our observation that ketamine did not change normal pain may indicate that the reduction of paradoxical pain was not due to an inhibition of HPC cells, but specifically to a reduction of the disinhibition of this nociceptive channel induced by the thermal grill. The fact that the subjects reported a mixture of warm and cool sensations suggests that the "warm and cool channels" were still functional, but that only the cold inhibition of cold-induced pain was blocked. Ketamine may have acted at the segmental level by blocking or reducing the segmental inhibition of COLD activity by warm afferents, putatively through a disynaptic inhibition of lamina I COLD cells. Alternatively, the glutamatergic blockade and the reduction of the desinhibition of the HPC channel could have been at the thalamo-cortical level. The corticofugal inputs to the thalamic sensory relay nuclei also involve glutamate and NMDA receptors (Salt and and Eaton, 1996; Salt, 2002). Thus, the reduction of paradoxical pain by ketamine may be the results of its action on the transmission of somatosensory signals and/or on the cortico-thalamic (top-down) modulation of sensory processes.

The selective effects of low doses of ketamine on paradoxical pain suggests that the thermal grill illusion of pain may share some mechanisms with pathological pain (inflammatory or neuropathic), particularly mechanical and thermal hyperalgesia/allodynia, which respond preferentially to NMDA antagonists both in animals and humans (Eide et al., 1994; Fundytus, 2001; Jorum et al., 2003; Chizh and Headley, 2005). This is consistent with the interpretation of the thermal grill effect according to the thermosensory disinhibition theory, which suggests that this phenomenon is related to the pathological mechanisms of spontaneous pain and/or 
cold allodynia frequently associated with central neurological lesion (Craig et al., 1994; Craig, 1998, 2003). Thus, in addition to being of interest for physiological studies, the thermal grill illusion of pain may also have clinical relevance. Analysis of this phenomenon in patients might be useful for studying the pathophysiology of pain in some clinical conditions (Heavner et al., 1997, Morin et al., 2002). Our study supports to the idea that it may also represent a unique experimental model of thermal allodynia.

At subanaesthetic doses, the effects of ketamine probably depend preferentially on the non competitive blockade of NMDA receptors through binding at the phencyclidine site. However, interactions with other receptors, including opioidergic, cholinergic and monoaminergic, alpha-amino-3-hydroxy-5-methyl-4isoxazole propionate (AMPA) receptors have also been reported, although generally only at higher concentrations (Finck and Ngai, 1982; Pekoe and Smith, 1982; Hustveit et al., 1995). Thus, the action of ketamine on non NMDA receptors cannot be formally excluded from involvement in the effects we report here. Further animal studies would help determine more precisely the site and mechanisms of the effects of ketamine on the paradoxical pain induced by a thermal grill.

All the subjects reported some side effects after the administration of ketamine but not after the placebo and therefore the study was not completely blind; this constitutes a limitation for the interpretation of our results. However, the remarkable selectivity of the action of ketamine on paradoxical pain makes unlikely that the results were due solely to nonspecific placebo effects. Such selective effects also argue against the possibility that our results were due to the well-documented action of ketamine on cognitive functions, particularly on attentional processes, rather than on the somatosensory systems. 
Our second study showed that iv naloxone had no effect on either the normal or paradoxical sensations induced by the thermal grill. Opioid receptors are widely expressed throughout the brain including in the structures involved in the processing and modulation of nociceptive and non nociceptive signals (Bodnar and Klein, 2004). Therefore, the opiodergic systems, at least those which are tonically active, do not appear to be involved directly in the production of the thermal grill illusion of pain. It is unlikely that these "negative" results were due to an insufficient dose, because in previous studies similar or lower doses of naloxone modulated complex responses related to pain perception such as the placebo effect or the experimental pain induced by capsaicin (e.g. Levine et al., 1979; Gracely et al.,, 1983; Anderson et al., 2002). However, our study does not rule out the involvement of endogenous opioids in this phenomenon. It would be necessary to study the effects of an opioid agonist (e.g. morphine) to investigate the putative role, if any, of actively stimulated opioid (in particular mu) receptors.

Acknowledgment: This work was supported by a grant from l'Institut UPSA de la Douleur. The authors thank Valérie Gaudé-Joindreau and Françoise Morain for technical assistance. 


\section{REFERENCES}

Alrutz. The sensation "hot". Mind 1898; 26: 141-144.

Anderson WS, Sheth RN, Bencherif B, Frost JJ, Campbell JN. Naloxone increases

pain induced by topical capsaicin in healthy human volunteers. Pain. 2002; 99: 207216.

Apkarian AV, Shi T. Squirrel monkey lateral thalamus. I. Somatic nociresponsive neurons and their relation to spinothalamic terminals. J Neurosci 1994; 14: 6779-95.

Bodnar RJ, Klein GE. Endogenous opiates and behavior: 2003. Peptides. 2004; 25 : 2205-2256

Boring EG. Tactual sensibility. In The History of Experimental Psychology. AppletonCentury-Crofts, New-York, 1942. pp. 463-521.

Bossard AE, Guirimand F, Fletcher D, Gaude-Joindreau V, Chauvin M, Bouhassira D. Interaction of a combination of morphine and ketamine on the nociceptive flexion reflex in human volunteers. Pain. 2002; 98: 47-57.

Bouhassira D, Kern D, Rouaud J, Pelle-Lancien E, Morain F. Investigation of the paradoxical painful sensation ('illusion of pain') produced by a thermal grill. Pain. 2005; 114: 160-167.

Brennum J, Kaiser F, Dahl JB. Effect of naloxone on primary and secondary hyperalgesia induced by the human burn injury model. Acta Anaesthesiol Scand. $2001 ; 45: 954-60$.

Buchsbaum MS Davis GC, Bunney WE. Naloxone alters pain perception and somatosensory evoked potentials in normal subjects. Nature 1977, $270: 620-2$.

Burton $\mathrm{H}$. Responses of spinal cord neurons to systematic changes in hindlimb skin temperatures in cats and primates. J Neurophysiol 1975; 38: 1060-79. 
Bushnell MC, Duncan GH, Tremblay N. Thalamic VPM nucleus in the behaving monkey. I. Multimodal and discriminative properties of thermosensitive neurons. J Neurophysiol 1993; 69: 739-52.

Chizh BA, Headley PM. NMDA antagonists and neuropathic pain-multiple drug targets and multiple uses. Curr Pharm Des. 2005;11: 2977-2994.

Collingridge GL, Lester RA. Excitatory amino acid receptors in the vertebrate central nervous system. Pharmacol Rev. 1989; 41: 143-210.

Craig AD, Bushnell MC. The thermal grill illusion: unmasking the burn of cold pain. Science 1994; 265: 252-5.

Craig AD, Krout K, Andrew D. Quantitative response characteristics of thermoreceptive and nociceptive lamina I spinothalamic neurons in the cat. J Neurophysiol 2001; 86: 145980

Craig AD, Reiman EM, Evans A, Bushnell MC. Functional imaging of an illusion of pain. Nature 1996; 384: 258-60

Craig AD. A new version of the thalamic disinhibition hypothesis of central pain. Pain Forum 1998; 7: 1-14.

Craig AD. R A new view of pain as a homeostatic emotion. Trends Neurosci. 2003;26 :303-7.

Defrin R, Ohry A, Blumen N, Urca G. Sensory determinants of thermal pain. Brain 2002; 125: $501-10$.

Dougherty PM, Palecek J, Paleckova V, Sorkin LS, Willis WD. The role of NMDA and non-NMDA excitatory amino acid receptors in the excitation of primate spinothalamic tract neurons by mechanical, chemical, thermal, and electrical stimuli. J Neurosci. 1992; 12: 3025-3041. 
Ducreux D, Attal N, Parker F, Bouhassira D. Mechanisms of central neuropathic pain: a combined psychophysical and fMRI study in syringomyelia. Brain. 2006; 129: 963976.

Eide PK, Jorum E, Stubhaug A, Bremnes J, Breivik H. Relief of post-herpetic neuralgia with the $\mathrm{N}$-methyl-D-aspartic acid receptor antagonist ketamine: a doubleblind, cross-over comparison with morphine and placebo. Pain. 1994; 58: 347-354.

Finck AD, Ngai SH. Opiate receptor mediation of ketamine analgesia. Anesthesiology. 1982; 56: 291-297.

Fruhstorfer $\mathrm{H}$, Harju EL, Lindblom UF. The significance of A-delta and $\mathrm{C}$ fibres for the perception of synthetic heat. Eur J Pain. 2003;7: 63-71

Fundytus ME. Glutamate receptors and nociception: implications for the drug treatment of pain. CNS Drugs. 2001; 15: 29-58.

Gracely RH, Dubner R, Wolskee PJ, Deeter WR. Placebo and naloxone can alter post-surgical pain by separate mechanisms. Nature. 1983; 306: 264-265.

Green BG. Synthetic heat at mild temperatures. Somatosens Mot Res 2002;19: 130-138.

Gregory RL. Knowledge in perception and illusion. Philos Trans R Soc Lond B Biol Sci. 1997; 352: 1121-1127.

Grevert P, Albert LH, Goldstein A. Partial antagonism of placebo analgesia by naloxone. Pain. 1983; 16: 129-143.

Guirimand F, Dupont X, Brasseur L, Chauvin M, Bouhassira D. The effects of ketamine on the temporal summation (wind-up) of the $\mathrm{R}$ (III) nociceptive flexion reflex and pain in humans. Anesth Analg. 2000; 90: 408-414.

Hansen C, Hopf HC, Treede RD. Paradoxical heat sensation in patients with multiple sclerosis. Evidence for a supraspinal integration of temperature sensation. Brain 1996; 119: 1729-36. 
Heavner JE, Calvillo O, Racz GB. Thermal grill illusion and complex regional pain syndrome type I (reflex sympathetic dystrophy). Reg Anesth. 1997; 22: 257-259.

Hustveit O, Maurset A, Oye I. Interaction of the chiral forms of ketamine with opioid, phencyclidine, sigma and muscarinic receptors. Pharmacol Toxicol. 1995; 77: 355359.

Jenkins WL. Studies in thermal sensitivity: further synthetic evidence against the Alrutz theory. J Exp Psychol 1938b; 23: 417-22.

Jenkins WL. Studies in thermal sensitivity: The reaction of untrained subjecs to simultaneous warm+cold stimulation. J Exp Psychol 1938a; 22: 451-61.

Jorum E, Warncke T, Stubhaug A. Cold allodynia and hyperalgesia in neuropathic pain: the effect of $\mathrm{N}$-methyl-D-aspartate (NMDA) receptor antagonist ketamine--a double-blind, cross-over comparison with alfentanil and placebo. Pain. 2003; 101: 229-235.

Kenshalo DR Jr, Leonard RB, Chung JM, Willis WD. Facilitation of the response of primate spinothalamic cells to cold and to tactile stimuli by noxious heating of the skin. Pain 1982; 12: $141-52$.

Khasabov SG, Cain DM, Thong D, Mantyh PW, Simone DA. Enhanced responses of spinal dorsal horn neurons to heat and cold stimuli following mild freeze injury to the skin. J Neurophysiol 2001; 86: 986-96.

Leung AY, Wallace MS, Schulteis G, Yaksh TL. Qualitative and quantitative characterization of the thermal grill. Pain. 2005; 116: 26-32.

Levine JD Gordon NC, Fields HL. Naloxone dose dependently produces analgesia and hyperalgesia in postoperative pain. Nature $1979 ; 278: 740-741$.

Mayer ML, Westbrook GL. The physiology of excitatory amino acids in the vertebrate central nervous system. Prog Neurobiol. 1987; 28: 197-276. 
McHaffie JG, Larson MA, Stein BE. Response properties of nociceptive and low-threshold neurons in rat trigeminal pars caudalis. J Comp Neurol 1994; 347: 409-25.

Morin C, Bushnell MC, Luskin MB, Craig AD. Disruption of thermal perception in a multiple sclerosis patient with central pain. Clin J Pain. 2002; 18: 191-195.

Moisset X, Bouhassira D.Brain imaging of neuropathic pain. Neuroimage. 2007;37 Suppl 1:S80-8.

Poulos DA, Benjamin RM. Response of thalamic neurons to thermal stimulation of the tongue. J Neurophysiol 1968; 31: 28-43.

Price DD, Hayes RL, Ruda M, Dubner R. Spatial and temporal transformations of input to spinothalamic tract neurons and their relation to somatic sensations. J Neurophysiol 1978; 41: 933-47.

Salt TE, Eaton SA. Functions of ionotropic and metabotropic glutamate receptors in sensory transmission in the mammalian thalamus. Prog Neurobiol. 1996; 48: 55-72.

Salt TE. Glutamate receptor functions in sensory relay in the thalamus. Philos Trans R Soc Lond B Biol Sci. 2002; 357: 1759-1766.

Strigo IA, Duncan GH, Bushnell MC, Boivin M, Wainer I, Rodriguez Rosas ME, Persson J. The effects of racemic ketamine on painful stimulation of skin and viscera in human subjects. Pain. 2005; 113: 255-264.

Thunberg T. Förnimmelserna vid till samma ställe lokasirerad, samtidigtb pagaende köld och värmeretning. Uppsala Läkkfören.Föhr. 1896: 489-95.

Yamasoto T, Pierau FRK. Different afferent temperature inputs of single dorsal horn neurones in rats. In International Congress of Physiology, Szelenyi and Szekeli (eds) 1980: 65-67.

Yosipovitch G, Yarnitsky D, Mermelstein V, Sprecher E, Reiss J, Witenberg C, Hemli JA, Boner G. Paradoxical heat sensation in uremic polyneuropathy. Muscle Nerve. 1995 ; 18: 768-71. 


\section{FIGURE LEGENDS}

Figure 1: Effects of ketamine on the paradoxical pain induced by a thermal grill.

A: The intensity of paradoxical pain measured on a Visual Analog Scale (VAS) was significantly lower after the administration of ketamine (black columns) than placebo (white columns). ( $F=8.2,{ }^{* *} p<0.01$, for the effect of the interaction period versus treatment).

B: The unpleansantness of paradoxical pain (i.e VAS score) was significantly lower after the administration of ketamine (black columns) than placebo (white columns). ( $F=12.9$; $p<0.01$, for the effect of the interaction period versus treatment).

Figure 2: A: Effects of ketamine on normal thermal pain induced by suprathreshold cold or heat stimuli. No significant change in pain intensity (i.e. VAS score) was observed after the administration of ketamine (black columns) or placebo (white columns).

B: Effects of ketamine on non painful warm and cold thermal sensations induced by stimuli at the warm and cool temperatures used to produce the paradoxical pain. No significant change in thermal sensations (i.e. intensity measured on VAS) was observed after administration of ketamine (black columns) or placebo (white columns).

Figure 3 : Effects of naloxone on paradoxical pain $(A)$ and normal cold $(B)$ and heat $(C)$ pain induced by a thermal grill. No significant change in paradoxical or normal pain intensity (i.e. VAS score) was observed after administration of naloxone (hatched columns) or placebo (white columns). 


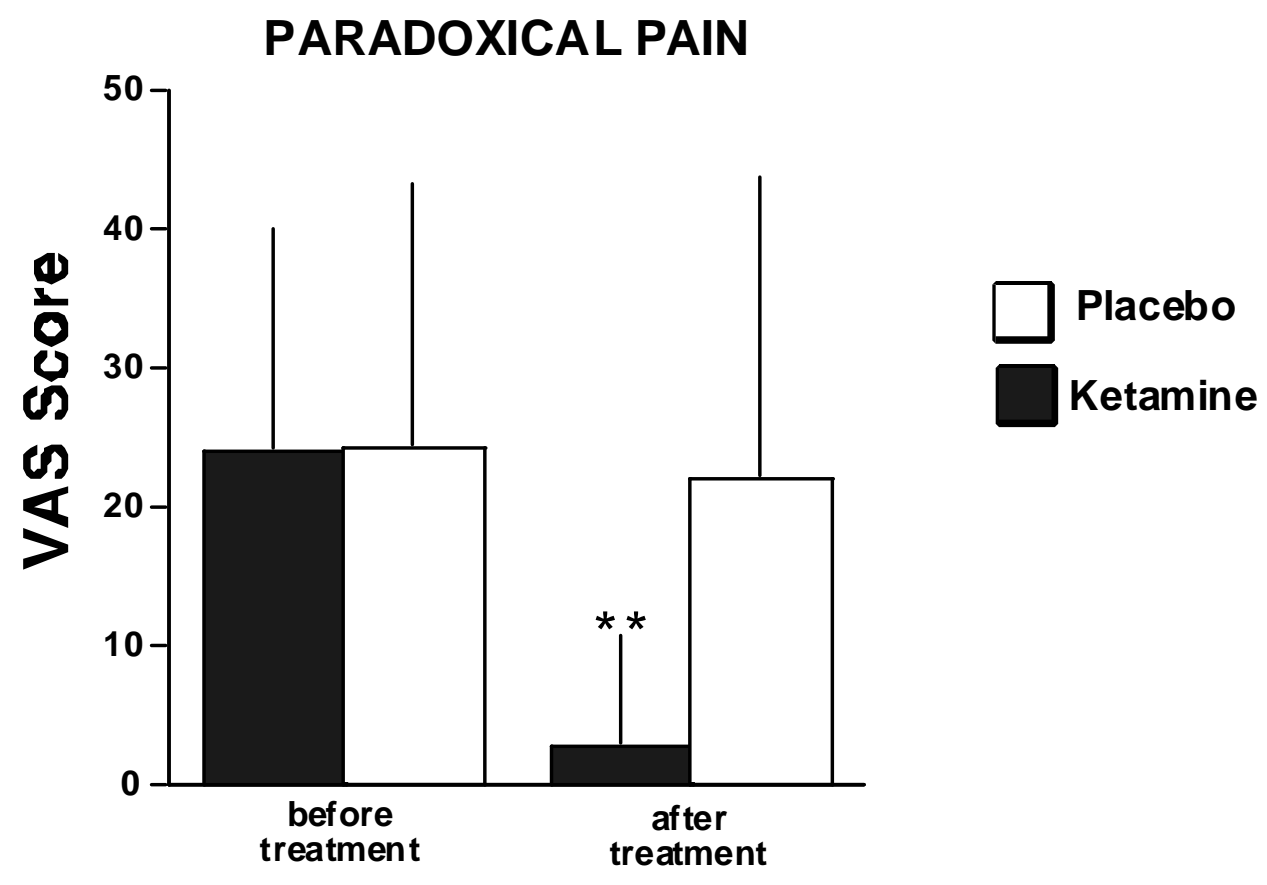

Figure 1 Kern et al. 

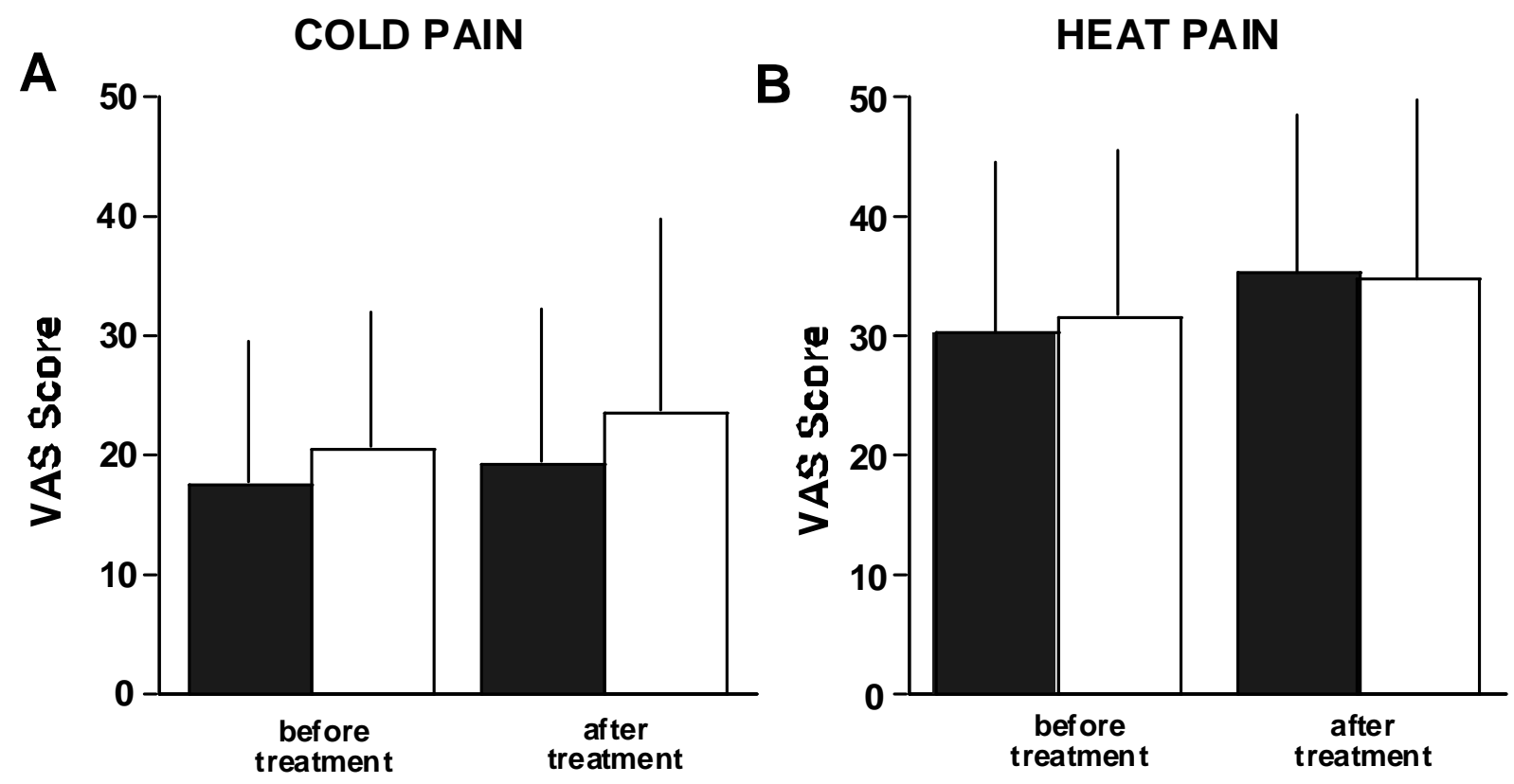

$\square$ Placebo

Ketamine

Figure 2 Kern et al. 

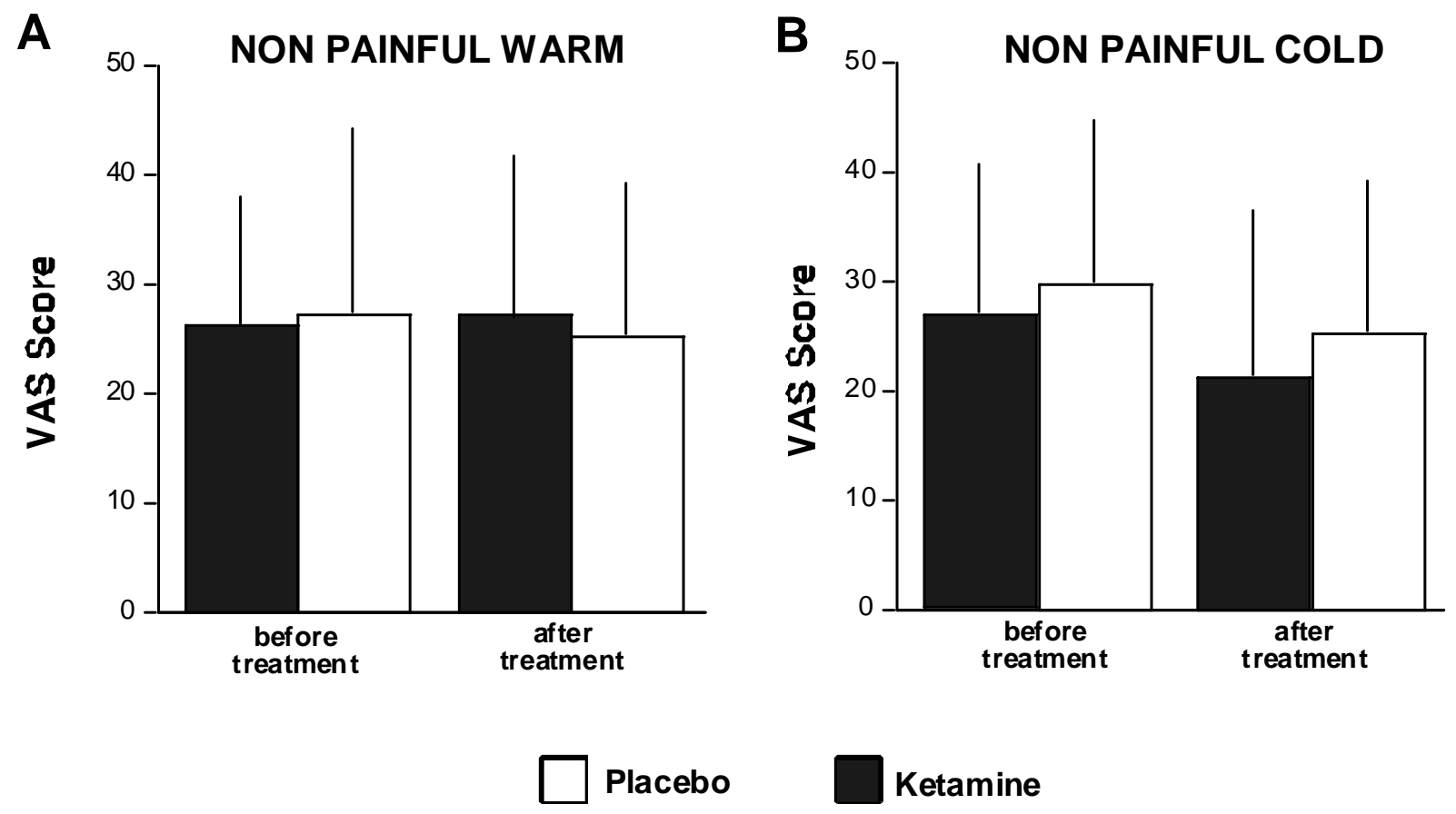

Figure 3 Kern et al. 
A PARADOXICAL PAIN

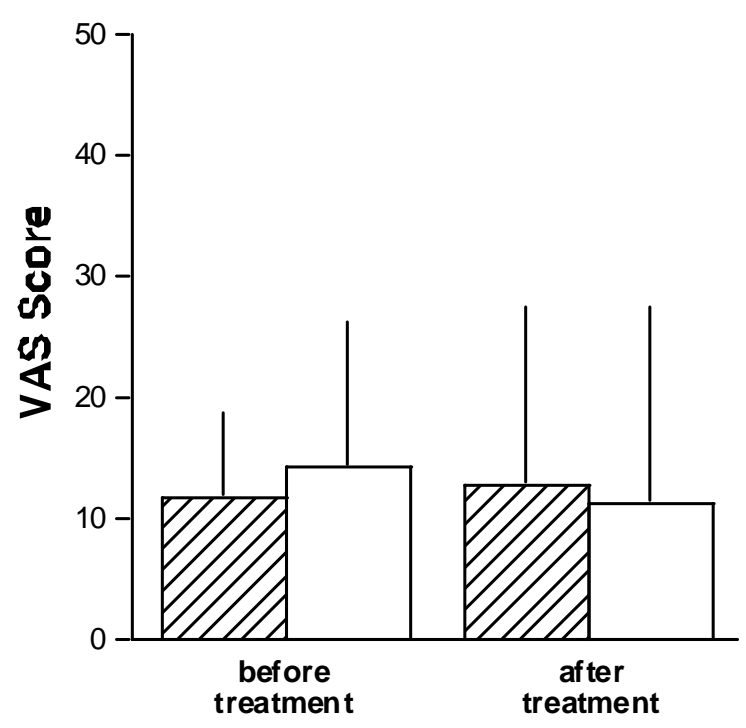

B

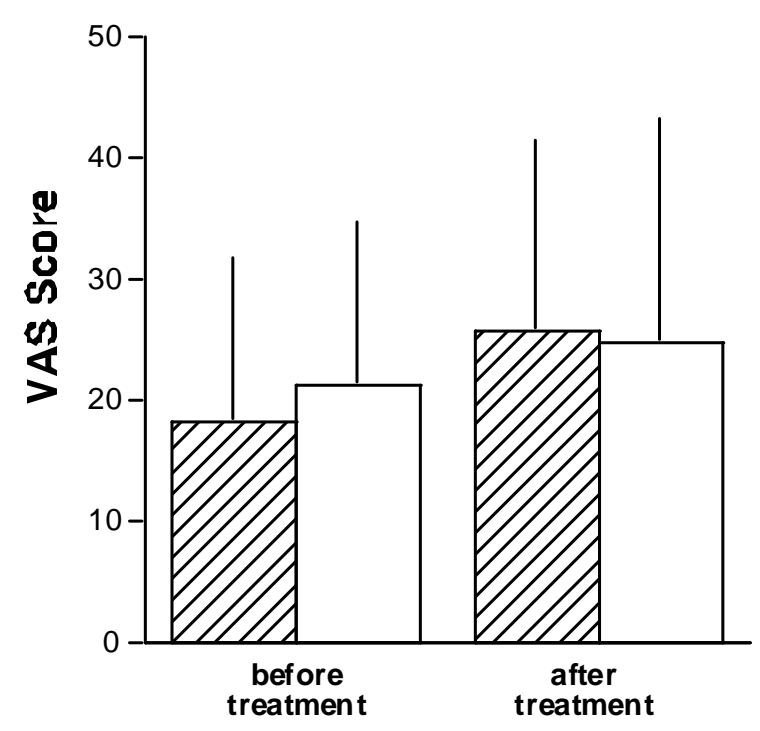

$\square$ placebo

$\square$ naloxone

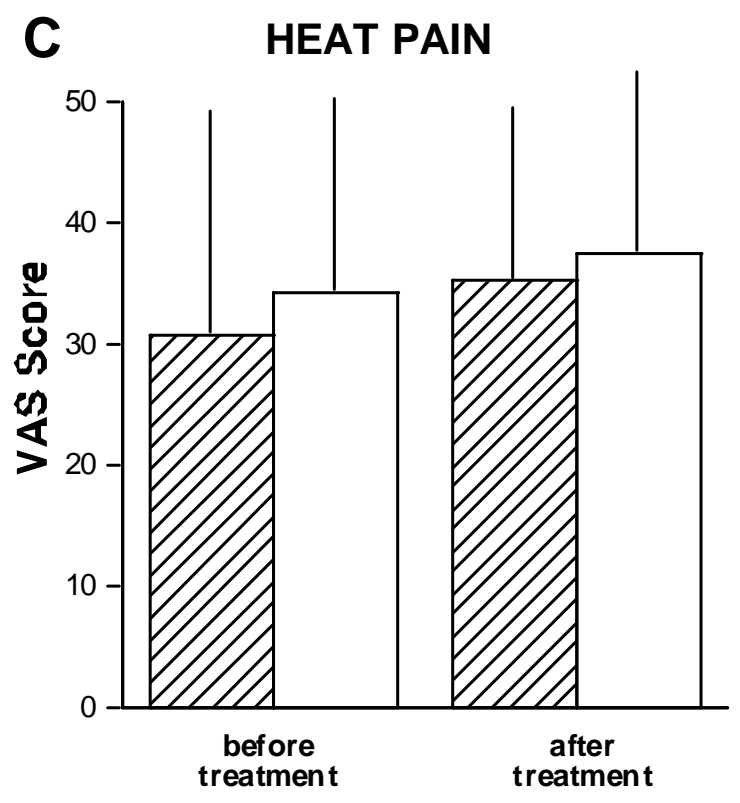

Figure 4 Kern et al. 